\title{
A FÓRMULA DA LEI UNIVERSAL E SUA APLICAÇÃO A CASOS CONCRETOS: CONSIDERAÇÕES SOBRE UMA CONHECIDA OBJEÇÃO
}

\author{
THE FORMULA OF UNIVERSAL LAW AND ITS APPLICATION IN CONCRET SITUATIONS: \\ CONSIDERATIONS ON A WELL-KNOWN OBJECTION
}

Elton Cândido Ribeiro*

\section{RESUMO}

Este artigo tem por objetivo demonstrar que a Fórmula da Lei Universal, tal como concebida por Kant, deve ser compreendida como um teste de permissibilidade da máxima. Para tanto, deverá também mostrar que a objeção à fórmula se fundamenta numa compreensão equivocada do conceito kantiano de máxima. Assim, num primeiro momento, será feita uma análise da derivação da fórmula a partir do conceito do imperativo categórico, tal como se apresenta na Segunda Seção da Fundamentação. Em seguida, serão analisados também os exemplos oferecidos por Kant naquela seção. Ato contínuo serão apresentados exemplos comuns da referida objeção. Na verdade, por três vezes, nessa obra, o filósofo chega a essa formulação, embora por meio de argumentos logicamente distintos: na Primeira Seção, a partir da análise do conceito de "boa vontade", presente no conhecimento moral comum; na Segunda, a partir do conceito do próprio imperativo categórico; na Terceira Seção, por fim, em função do conceito negativo de liberdade. O artigo se encerra com a consideração do conceito kantiano de máxima, a partir das três definiç̧̃es dela que o filósofo ofereceu.

PALAVRAS-CHAVE: Fundamentação da Metafísica dos costumes. Imperativo Categórico. Fórmula da Lei Universal. Máxima.

\section{ABSTRACT}

This paper aims to demonstrate that Kant's Formula of Universal Law should be understood as a test of the permissibility of the maxims. To do so, it must also show that the objection to the formula is based on a misunderstanding of the Kantian concept of maxim. Thus, in the first instance, an analysis of the derivation of the formula from the concept of the categorical imperative will be made, as presented in the Second Section of the Groundwork. Next, the examples offered by Kant in that section will also be analyzed. Common examples of that objection will be presented below. In fact, three times in this work, the philosopher arrives at this formulation, albeit by means of logically distinct arguments: In the First Section, from the analysis of the concept of "good will" present in the common moral knowledge; in the second, from the concept of the categorical imperative itself; in the Third Section, finally, due to the negative concept of freedom. The article closes with the consideration of the Kantian concept of maxim, from the three definitions of it that the philosopher offered.

KEYWORDS: Groundwork for the Metaphysics of Morals. Categorical Imperative. Formula of Universal Law. Maxim.

\footnotetext{
* Doutorando em Filosofia pela PUC-SP (bolsista da CAPES). Mestre em Filosofia pela mesma instituição. Bacharel em Teologia pelo CES/JF. E-mail: elton_mail@yahoo.com.br.
} 


\section{INTRODUÇÃO}

A assim chamada "fórmula da lei universal" é a primeira formulação do princípio supremo da moralidade (imperativo categórico) apresentada por Immanuel Kant na Fundamentação da metafísica dos costumes. Na verdade, por três vezes, nessa obra, o filósofo chega a essa formulação, embora por meio de argumentos logicamente distintos: na Primeira Seção, a partir da análise do conceito de "boa vontade", presente no conhecimento moral comum; na Segunda, a partir do conceito do próprio imperativo categórico; na Terceira Seção, por fim, em função do conceito negativo de liberdade.

A Fórmula da Lei Universal, aparentemente, apresenta-se como uma maneira simples e eficiente de se aplicar o imperativo categórico às situações morais concretas. Bastaria realizar o teste de universalizabilidade com a máxima em questão para saber se a ação pretendida está ou não de acordo com a lei moral. Esta seria sua função negativa: atuar como um teste de permissibilidade da máxima. Além disso, há quem veja nela, a partir dos exemplos apresentados pelo filósofo na Segunda Seção, também um papel positivo: o da derivação de deveres concretos.

Na prática, todavia, o teste de universalizabilidade da máxima apresenta dificuldades. Estudiosos foram capazes de identificar situações hipotéticas em que o teste reprova máximas intuitivamente ingênuas, bem como autoriza máximas que claramente violam a lei moral. Esse fato serviu de mote para que a fórmula fosse considerada algo menos do que um teste de permissibilidade ou algoritmo moral - no máximo, um expediente para uma pré-deliberação moral ou, ainda, um passo sistemático na direção das demais fórmulas do imperativo categórico, talvez mais importantes e prolíficas do ponto de vista prático.

Este artigo tem por objetivo demonstrar que a Fórmula da Lei Universal, no entendimento de Kant, deve ser compreendida como um teste de permissibilidade da máxima. Para tanto, deverá mostrar também que a objeção à fórmula se fundamenta numa compreensão equivocada do conceito kantiano de máxima. Assim, num primeiro momento, será feita uma análise da derivação da fórmula a partir do conceito do imperativo categórico, tal como se apresenta na Segunda Seção da Fundamentação. Em seguida, serão analisados também os exemplos oferecidos por Kant naquela seção. Ato contínuo, serão apresentados exemplos comuns da referida objeção. $\mathrm{O}$ artigo se encerra com a consideração do conceito kantiano de máxima, a partir das três definições dela que o filósofo ofereceu. 


\section{A DERIVAÇÃO DA FÓRMULA A PARTIR DO CONCEITO DO IMPERATIVO}

Após adiar, até a Terceira Seção, a discussão sobre a possibilidade do imperativo categórico, Kant se propõe derivar sua fórmula a partir do mero conceito do imperativo. Ora, no que se refere a um imperativo hipotético, seu conteúdo só pode ser determinado quando se é apresentada a condição - ou seja, quando se leva em conta um determinado fim a que o agente racional se propõe perseguir. Algo diferente acontece com o imperativo categórico: ao representá-lo em pensamento, percebe-se que ele contém apenas lei moral universal e necessária em seu aspecto formal, à qual a máxima do sujeito deve se conformar.

Do ponto de vista da universalidade da lei, portanto, o imperativo categórico pode ser assim formulado: "age apenas segundo aquela máxima pela qual ao mesmo tempo tu possas querer que se torne uma lei universal" ${ }^{\prime 1}$ (GMS 4: 42, grifos do autor) ${ }^{2}$. Esta é a chamada Fórmula da Lei Universal (FLU). E como o conceito de lei universal está estreitamente relacionado ao conceito de natureza, o filósofo apresenta, logo em seguida, uma primeira variação da fórmula fundamental, a chamada Fórmula da Lei da Natureza (FLN): “age de tal modo como se a máxima da tua ação, através da tua vontade, devesse se tornar uma lei universal da natureza"3.

Essa derivação do imperativo causou desconforto a alguns. Com efeito, teve-se a impressão de que Kant, sub-repticiamente, saltou de um conceito meramente formal (e, neste sentido, vazio) para a fórmula do imperativo propriamente dita. Noutros termos, como o filósofo pôde derivar da vacuidade de um princípio de mera conformidade à universalidade da lei uma fórmula prenhe de significado, onde se considera também a máxima particular e a vontade de um ser racional finito? Uma forma de lidar com essa dificuldade passa pela compreensão de uma distinção na filosofia teorética, adotada pelo filósofo prussiano em consonância com a tradição aristotélica, entre "matéria" e "forma": "o primeiro significa o determinável em geral, o segundo a determinação deste" (KrV A266 = B322). Do ponto de vista lógico, a matéria tem precedência. Algo deve ser dado em primeiro lugar para depois ser

\footnotetext{
1 “handle nur nach der derjenigen Maxime, durch die du zugleich wollen kannst, daß sie ein allgemeines Gesetz werde". Nesta e nas traduções que seguem, faço opção por me ater à literalidade do texto, ainda que o estilo, em função disso, revele-se pouco atraente.

${ }^{2}$ Referências à obra de Kant fazem remissão à edição da Akademie-Ausgabe, considerando, nesta ordem, a sigla da obra (GMS - Grundlegung zur Metaphysik der Sitten), o número do volume e da página na edição da Academia. A Crítica da Razão Pura, porém, será referida pela sigla $(K r V)$, seguida da paginação das edições A (1781) e B (1787). A Grundlegung, em alguns casos, será referida simplesmente como Fundamentação.

3 "handle so, als ob die Maxime deiner Handlung durch deinen Willen zum allgemeinen Naturgesetze werden sollte".
} 
determinado. Do ponto de vista epistemológico, porém, a forma ganha a precedência: as formas da sensibilidade são condição para que os objetos sensíveis nos sejam dados na experiência e, os conceitos do entendimento, para que estes sejam pensados. Essa evidente inversão é realizada pelo filósofo também na filosofia moral: a forma (e não mais a matéria, como nas teorias morais tradicionais) é que tem força normativa. Ela se torna condição da moralidade da ação. Todavia, a lei moral, no seu aspecto necessário e universal, apresenta-se concretamente a um ser racional-sensível, cuja vontade nem sempre se adéqua às exigências morais apresentadas pela razão. Daí a presença da máxima do sujeito na formulação do imperativo: a fórmula expressa, justamente, a relação entre a lei moral e uma vontade imperfeitamente racional ${ }^{4}$.

Uma vez derivada a fórmula do imperativo, Kant tratará de aplicá-la a quatro casos concretos, o que sugere, em primeiro lugar, que ela é adequadamente compreendida em sentido negativo ou restritivo em relação à máxima, ou seja, como um teste de permissibilidade da máxima, através de sua universalização. Todavia, o texto da Segunda Seção permitiu a alguns intérpretes entreverem também um sentido positivo na fórmula, a saber, a possibilidade de derivar, a partir dela, deveres específicos. Essa interpretação encontra amparo no texto. De fato, logo após apresentar a primeira fórmula, o filósofo acrescenta: "Se, agora, deste único imperativo, todos os imperativos do dever, como de seu princípio, podem ser derivados [...]" (GMS 4: 421). Kant realmente utiliza o verbo ableiten, “derivar”, na forma do particípio (abgeleitet). Isso dá a entender que a fórmula do imperativo cumpre o papel, certamente desejado num sistema moral, de ser fonte para a derivação de deveres positivos. Muito naturalmente, o filósofo poderia estar, por conseguinte, derivando deveres nos exemplos que forneceu. Na esteira dessa compreensão, alguns tradutores substituem a palavra Abteilung (repartição) por Ableitung (derivação) na sentença conclusiva aos quatro exemplos supracitados ${ }^{5}$. Se se tratasse meramente de uma repartição ou classificação de deveres, ele poderia ter utilizado a palavra Einteilung (divisão).

Todavia, há, igualmente, boas razões para se manter o original Abteilung e, assim, manter a interpretação que atribui ao teste apenas um papel negativo ou restritivo, ou seja, que Kant esteja apenas enumerando deveres já conhecidos e aplicando aos casos concretos de seus

\footnotetext{
${ }^{4}$ Esta é a abordagem de Allison (2011, p. 172-175).

${ }^{5}$ Esta é a opção, por exemplo, da conhecida tradução de Paulo Quintela: "Estes são apenas alguns dos muitos deveres reais ou que pelo menos nós consideramos como tais, cuja derivação do princípio único acima exposto ressalta bem clara” (GMS 4: 421; p. 214 da tradução, grifo nosso). No original, porém, lê-se: „Dieses sind nun einige von den vilen wirklichen oder wenigstens von uns dafür gehaltenen Pflichten, deren Abteilung [repartição] aus dem einigen angeführten Prinzip klar in die Augen fällt" (grifo nosso).
} 
Artigo: A fórmula da lei universal e sua aplicação a casos concretos: considerações sobre uma conhecida objeção

exemplos o teste da universalizabilidade da máxima. Em primeiro lugar, ele parece mais preocupado em mostrar a relação de seu princípio com deveres determinados do que propriamente em derivá-los: "Agora queremos enumerar alguns deveres, segundo a divisão habitual dos mesmos em deveres para conosco mesmos e para com outros homens, em deveres perfeitos e imperfeitos" (GMS 4: 421). Em segundo lugar, não é possível afirmar, quando Kant fala da derivação de deveres, que deva se restringir às duas fórmulas acima ou que precise do sistema inteiro de fórmulas - sugestivamente, seu procedimento na futura Metafísica dos costumes parece confirmar a segunda alternativa (WOOD, 1999, p. 40-41, nota $52)$.

Assim, a função da Fórmula da Lei Universal é tão somente possibilitar a verificação da moralidade da máxima mediante o teste da universalizabilidade, sem, contudo, indicar deveres positivos com os resultados do teste. A análise seguinte dos exemplos de Kant tornará ainda mais clara essa função.

\section{OS EXEMPLOS DE KANT}

Kant, na Segunda Seção da Fundamentação, apresenta quatro exemplos de aplicação do imperativo categórico a casos morais concretos, organizados segundo a divisão dos deveres que ele próprio apresentou e que considera habitual em seu tempo: deveres perfeitos e imperfeitos, deveres para com nós mesmos e para com os outros. Ao final dos exemplos que apresentar, o filósofo indicará com mais clareza o princípio dessa divisão: a máxima que viola um dever perfeito não pode sequer ser pensada pelo sujeito sem contradição. Já a máxima que desrespeita um dever imperfeito pode ser pensada, mas não querida por ele. Assim, de acordo com a natureza do dever, o teste de universalizabilidade da máxima pode apresentar duas ordens de contradição: a contradição no conceito (os dois primeiros exemplos) e a contradição na vontade (os dois últimos) ${ }^{6}$.

\footnotetext{
${ }^{6}$ É importante ter em mente essas duas formas do teste. Alguns filósofos pensaram que bastaria, para a aprovação da máxima, não incorrer em contradição de conceito no teste e que, dessa forma, algumas máximas imorais poderiam passar por ele. Esse é o caso, por exemplo, de Hegel e Stuart Mill. Aquele afirma na Fenomenologia do Espírito: "Mas por essa razão é que o examinar não vai longe, porque justamente o padrão de medida é a tautologia: indiferente ao conteúdo, acolhe em si tanto este conteúdo quanto o oposto" (HEGEL, 2011, §430; p. 298). Mill, em Utilitarianism, é bem mais explícito: "Mas quando ele [Kant] começa a deduzir deste preceito quaisquer dos atuais deveres da moralidade, falha, quase grotescamente, em mostrar que não haveria nenhuma contradição, nenhuma impossibilidade lógica (para não dizer física), na adoção de regras de conduta as mais absurdamente imorais por todos os seres racionais" (MILL, 1969, p. 207).
} 
a) Suicídio. Alguém que, diante dos males que cercam sua existência, prefere abreviar o curso de sua vida, tem como máxima: "tomo por princípio, por amor-próprio, abreviar minha vida, sempre que ela, ao se prolongar sua duração, mais me ameaçar com maiores males do que me prometer amenidade" (GMS 4: 422). Ora, esse princípio do amor de si foi dado a nós pela natureza para promover nossa própria vida. Por conseguinte, ao se considerar essa máxima como uma lei universal, ver-se-ia uma natureza em contradição consigo mesma, permitindo a alguém tirar a própria vida pela mesma sensação que lhe foi dada para promovê-la.

O exemplo não deixa de ser problemático. Ao invés de revelar propriamente uma contradição no conceito ou na vontade, Kant lança mão de um princípio teleológico, com o qual a máxima está em contradição. Noutros termos, não se vê imediatamente uma contradição entre a máxima e ela mesma elevada à lei universal da natureza, mas entre ela e um princípio teleológico exterior ao próprio argumento. Sem dúvida, Kant ilustra um dever não controverso (a imoralidade do suicídio era aceita, em seu tempo, sobretudo por motivos religiosos), o que pode fazer com que a dificuldade passe despercebida. Claro está, porém, que aceitar a Fórmula da Lei Universal ou sua variação não implica, do ponto de vista lógico, aceitar a imoralidade do suicídio (WOOD, 1999, p. 84-86).

b) Falsa promessa. O segundo exemplo diz respeito a alguém que, num apuro financeiro, por exemplo, vê-se obrigado a fazer uma promessa que sabe que não poderá cumprir. O teor de sua máxima é: "se eu acreditar que estou em dificuldades financeiras, pedirei dinheiro emprestado e prometerei pagar, ainda que eu saiba que isso nunca acontecerá" (GMS 4: 422). Claramente surge, através do teste de universalizabilidade, uma contradição no conceito: se a falsa promessa fosse lei universal, a própria instituição "promessa" deixaria de existir. Sutilmente, porém, parece ser indicada também uma contradição na vontade, pois se afirma que, ao proceder dessa maneira, o sujeito não obteria o fim que desejaria com isso (den man damit haben mag). São possíveis, desse modo, uma interpretação lógica e uma prática do exemplo (WOOD, 1999, p. 87-89).

c) Negligência para com os próprios dons. No terceiro exemplo, considera-se a máxima de alguém que poderia ser útil à sociedade se se empenhasse em desenvolver seus dons e talentos, mas que prefere entregar-se ao deleite da própria vida. O que ocorreria se essa máxima fosse submetida ao teste da universalizabilidade? Nenhuma contradição no conceito seria, de fato, revelada (pois se trata de um dever imperfeito). Kant acredita, todavia, revelar uma contradição na vontade. Mais uma vez, é preciso notar, lança mão de um princípio exterior ao argumento, de tipo teleológico, a saber, o princípio segundo o qual há coisas que 
Artigo: A fórmula da lei universal e sua aplicação a casos concretos: considerações sobre uma conhecida objeção

um ser racional deseja necessária e incondicionalmente. Como ser racional, ele tem que desejar que todas as suas faculdades se desenvolvam, pois lhe foram "dadas" (pela natureza, presume-se), para todo tipo de fins possíveis.

d) Indisposição para a benevolência. Por fim, apresenta-se alguém que é indiferente à vida do próximo, seja ao seu bem-estar seja ao seu sofrimento. Tal máxima é submetida, igualmente, ao teste da universalizabilidade. Ora, embora não se manifeste contradição conceitual alguma, o sujeito em questão, enquanto ser racional, certamente não poderia desejar um mundo onde sua máxima valesse como lei universal em todos os tempos e lugares, pois, uma vez que não é autossuficiente em relação às próprias necessidades, deverá pensar no seu interesse ${ }^{7}$ oportunamente, poderá também ele precisar do auxílio alheio. Subjaz ao exemplo o princípio empírico que afirma a interdependência entre os seres humanos: não somos autossuficientes; somos vulneráveis às ameaças e aos diversos infortúnios da vida e precisamos da colaboração dos outros para a realização de nossos próprios fins.

Esta rápida passagem pelos exemplos de Kant na Segunda Seção da Fundamentação torna problemática a função da Fórmula da Lei Universal já mencionada acima: a de ser um teste de permissibilidade da máxima. Com efeito, o uso recorrente de princípios exteriores ao teste, seja de ordem teleológica ou empírica, parece corroborar a ideia de que a fórmula é provisória e até insuficiente para um teste desse jaez. É o caso de Barbara Herman (1993, p. 147-151), para a qual é bastante manifesta a dificuldade de se aplicar um teste por demais abstrato e universal às máximas particulares do sujeito na sua concretude. A função do teste seria bem menos do que oferecer um "algoritmo" para a deliberação moral. Ele não se aplicaria às máximas do sujeito, mas apenas a máximas mais genéricas, tendo como resultado um conhecimento moral pré-deliberativo, suposições morais que poderiam figurar como elementos de uma posterior deliberação moral e, desse modo, serem confirmadas ou refutadas. Num outro viés, Allen Wood (1999, p. 97-110), frente a essas dificuldades, prefere considerar a Fórmula da Lei Universal uma versão provisória e parcialmente bem-sucedida do princípio supremo da moralidade. Ela não tem valor em si, mas apenas enquanto parte de um

\footnotetext{
${ }^{7}$ A referência ao interesse próprio fez com que Schopenhauer, por exemplo, interpretasse o ajuizamento moral presente no exemplo como fundado no amor-próprio ou egoísmo: "Na ética, contudo, onde o objeto de investigação é a ação enquanto ação e no seu significado imediato para o agente - mas não sua consequência, a saber, o sofrimento, ou sua referência aos outros - aquela consideração [do exemplo em questão] é completamente inadmissível, uma vez que no fundo isso equivale a um princípio de felicidade e, portanto, ao egoísmo" (SCHOPENHAUER, 1969, p. 526 - grifos do autor). Não se trata de egoísmo, porém, mas do reconhecimento de sua insuficiência em socorrer-se por si mesmo em suas próprias necessidades. Um ser racional reconhece, simplesmente, que não é autossuficiente e que necessita da concorrência de outros seres racionais para a realização de seus fins.
} 
desenvolvimento sistemático que levará às outras formulações do princípio, que serão mais úteis e adequadas do ponto de vista prático. Wood, por fim, considera que tal limitação da fórmula é decorrente de um "defeito congênito": sua derivação falaciosa a partir do "mero" conceito do imperativo.

Essas objeções se referem aos exemplos apresentados pelo filósofo. Soma-se a elas uma objeção conhecida, a saber, de que o teste poderia reprovar máximas intuitivamente inocentes do ponto de vista moral, bem como aprovar máximas que claramente violam o princípio moral. É o caso dos chamados falso-positivos e falso-negativos do teste de universalizabilidade, que serão analisados a seguir.

\section{UMA OBJEÇÃO COMUM: OS FALSO-POSITIVOS E FALSO-NEGATIVOS DO TESTE}

A literatura secundária oferece diversos exemplos, com boa dose de criatividade, de máximas que, ou são imorais, mas passam despercebidas pelo teste, ou são inocentes e, todavia, reprovadas por ele. São os assim chamados "falso-positivos" e "falso-negativos" do teste.

a) Falso-positivo: Allen Wood (1999, p. 102) dá um exemplo emblemático deste caso. Considere-se a máxima "fazer uma falsa promessa, na terça-feira, dia 21 de agosto, a uma pessoa chamada Hildreth Milton Flitcraft”. É intuitivamente perceptível que a máxima é imoral. Porém, espantosamente, quando ela é submetida ao teste de universalizabilidade, não se revela nenhuma contradição no conceito ou na vontade. Do ponto de vista lógico, a instituição promessa não é comprometida, pois, num mundo onde fazer uma falsa promessa a um sujeito numa data determinada fosse uma lei universal, as demais promessas feitas a outras pessoas em outros tempos e lugares ainda teriam seu valor. O resultado, ademais, não estaria em contradição com a vontade do sujeito: evidentemente, esse seria um mundo bem desejável por ele. Diante de uma máxima tão específica - e este é o caso de muitas das máximas que motivam nossas ações no dia a dia - o teste se revela ineficaz em denunciar sua imoralidade.

b) Falso-negativo: Considerem-se, agora, máximas que são condenadas pelo teste, mas que são inocentes do ponto de vista moral.

1) Comprarei um trenzinho de brinquedo, mas jamais venderei um; 
Artigo: A fórmula da lei universal e sua aplicação a casos concretos: considerações sobre uma conhecida objeção

2) A fim de evitar quadras de tênis cheias, jogarei aos domingos de manhã, quando meus vizinhos estão na igreja e as quadras estão livres;

3) Quando o índice Dow-Jones alcançar o próximo milhar, venderei todas as minhas ações ${ }^{8}$;

4) Jantarei, às segundas-feiras, na casa dos amigos (BITTNER, 2003, p. 11);

Percebe-se que todos os exemplos implicam contradições de ordem lógica ou também na ordem da vontade, dependendo da interpretação. Caso (1) fosse uma lei universal da natureza, extinguir-se-ia a venda de trenzinhos de brinquedo (contradição no conceito) e essa também não seria uma situação desejável pelo sujeito em questão, que quer adquirir um (contradição na vontade). No segundo exemplo, o jogo de tênis não deixaria de existir (apenas aos domingos de manhã!), mas o sujeito não conseguiria alcançar a finalidade que perseguia antes (contradição na vontade). O mesmo se diga de (3) e de (4).

Esses rápidos exemplos parecem reforçar a objeção supramencionada: talvez a Fórmula da Lei Universal não possa ser, nem mesmo, um teste de permissibilidade da máxima, mas, quando muito, um pré-teste ou ainda um primeiro passo sistemático rumo à elaboração das demais formulações do princípio supremo da moralidade, bem mais adequadas do ponto de vista moral. Afinal, para máximas tão particulares, o teste não tem valor objetivo.

Contudo, cabem, aqui, algumas observações. Primeiramente, no caso do falso-positivo de Wood, Flitcraft jamais acreditaria numa lei universal segundo a qual ele seria enganado num dia específico - lei da qual ele teria conhecimento. Ademais, embora a situação descrita por Wood se pareça com a situação descrita no segundo exemplo de Kant, há diferenças notórias: o mentiroso, no exemplo do filósofo, é um indivíduo consciente que, mesmo tentado a fazer uma falsa promessa numa situação de apuro financeiro, ainda tem bastante consciência para se perguntar pela moralidade do ato. Já o mentiroso de Wood não está preocupado com a moralidade do ato, mas tão somente em burlar o teste da universalizabilidade. Por fim, o mais curioso é o alto grau de especificidade da máxima empregada neste e nos outros exemplos: a maneira como se formula a máxima interfere diretamente no resultado do teste - e Kant parece não ter dado um critério claro e objetivo para a determinação daquilo que ele próprio chama de "máxima". . Os fundamentos das ações nos exemplos apresentados são, de fato,

\footnotetext{
${ }^{8}$ Os três primeiros exemplos foram recolhidos por Wood (1999, p. 105).

${ }^{9}$ Segundo David Ross (1954, p. 32-33), de acordo com o nível de especificidade da máxima, o resultado do teste pode variar. Por exemplo, a mentira contada a um possível assassino pode se enquadrar na subespécie "mentiras contadas a pessoas assassinas" ou na espécie "mentiras". No segundo caso, ela não passaria no teste, mas no primeiro sim (ao menos na sua visão), de modo que aquele que contou uma mentira a um assassino para salvar uma vida, diante das exigências do teste de universalizabilidade, certamente diria: "Penso que a sociedade humana seria melhor conduzida se as pessoas habitualmente contassem mentiras em tais circunstâncias do que se
} 
máximas ou regras práticas e intenções específicas? Assim, a pergunta se desloca: afinal, o que são "máximas” na acepção kantiana?

\section{O CONCEITO KANTIANO DE MÁXIMA}

$\mathrm{Na}$ tentativa de esclarecer a questão, Rüdiger Bittner (2003, p. 8) aponta três passagens textuais no opus kantiano em que o conceito de "máxima" é definido expressamente: (i) “Máxima é o princípio subjetivo do querer; o princípio objetivo (i.e. aquilo que serviria para todos os seres racionais também subjetivamente como princípio prático, se a razão tivesse plena autoridade sobre a faculdade do apetite) é a lei prática" (GMS 4: 400, nota); (ii) "Máxima é o princípio subjetivo para agir e deve ser diferenciado do princípio objetivo, a saber, a lei prática" (GMS 4: 420, nota); (iii) "Princípios práticos são princípios que contêm uma determinação geral da vontade, a qual tem sob si simples regras práticas. Eles são subjetivos, ou máximas, se a condição for considerada pelo sujeito como válida somente para sua vontade; porém, princípios objetivos ou leis práticas, se aquela for reconhecida como objetiva, ou seja, válida para a vontade de todo ser racional" ( $K p V 5: 35)$.

As definições supracitadas concordam que as máximas são princípios ${ }^{10}$ que determinam o querer ou o agir. Esta ainda é, todavia, uma definição muito geral, que não permite distinguir, sem mais, uma máxima de uma regra ou propósito subjetivo. Seria a máxima, por conseguinte, apenas um tipo de lei, uma certa regularidade a ser identificada no agir subjetivo? Para dirimir essa questão, é necessário compreender que tipo de regra é a máxima e qual deve ser o grau exato de sua generalidade para que seja considerada como $\operatorname{tal}^{11}$.

Em primeiro lugar, a máxima é, sim, uma regra presente no comportamento do sujeito. Não é, todavia, a regularidade assinalada por um observador externo, pois isso não indica que ele seja consciente dessa regra ou que a deseje como tal. Aqui está, precisamente, a diferença entre a máxima e uma regra comportamental: a máxima é querida pelo sujeito. Nos exemplos acima, Kant sempre indica que o sujeito tomou para si uma máxima e não apenas teve uma máxima. Noutras palavras, o filósofo faz questão que o leitor perceba que não está identificando, como observador externo, uma regra presente no comportamento daquelas

elas habitualmente contassem a verdade e ajudassem assassinos a cometerem seus crimes". Sobre as considerações em relação ao exemplo de Wood, ver Allison (2011, p. 190-193).

${ }^{10}$ Rüdiger Bittner (2003, p. 8) traduz Grundsätze por "proposições fundamentais”.

${ }^{11}$ Leva-se em consideração, aqui, a análise de Bittner (2003, p. 8-16). 
Artigo: A fórmula da lei universal e sua aplicação a casos concretos: considerações sobre uma conhecida objeção

pessoas, mas que estas estão conscientes desta regra e a desejam como tal - ainda que tenham, antes, consciência para se perguntar se a máxima está ou não em acordo com a lei moral. Assim, toda máxima expressa uma regra passível de ser identificada em meu agir, mas nem toda regra que nele se perceba é uma máxima.

Tal nota definitória é, entretanto, insuficiente, pois regras da vida cotidiana e propósitos específicos também possuem máximas. Assim, em segundo lugar, é preciso determinar com exatidão o grau de generalidade da máxima. Este não é um problema simples. Não se trata de considerar que a máxima abarque mais casos que uma regra - regras podem, também, abarcar grande quantidade de casos. Muito menos de afirmar que a máxima tenha de valer por mais tempo: uma regra, como a de se levantar todos os dias às sete da manhã, pode ser mantida por toda uma vida.

A generalidade da máxima pode ser indicada pela diferença entre mudança de propósitos e casos de abandono de máximas. Aparentemente, uma máxima pode ser abandonada com a mesma facilidade que uma regra - os exemplos de Kant são prova disso. Contudo, ao se olhar mais de perto, percebe-se que, embora uma regra do agir possa ser mudada pelo conhecimento de fatos particulares, uma máxima, por sua vez, só é mudada quando há fatos bem mais gerais ou, propriamente, razões morais. Por exemplo, considere-se a máxima "jantarei às segundas-feiras à noite na casa dos amigos". Esse propósito pode ser mudado facilmente ao se constatar a existência de um bom seriado exibido pela televisão às segundas-feiras à noite. $\mathrm{O}$ mesmo não se dá com a máxima. Um avarento considera mudar a máxima que subjaz ao seu comportamento porque percebe que se sacrifica demais pela riqueza ou que é rejeitado pelos seus semelhantes por isso. Mais do que um fato particular, ele considera a orientação de sua vida como um todo, o tipo de ser humano que se tornou - uma visão global que jamais vem à baila numa mera mudança de regra ou propósito. Assim, indica Bittner (2003, p. 14): "Máximas são regras de vida: elas expressam que tipo de ser humano eu quero ser - alguém que ninguém pode insultar impunemente; ou alguém a quem não interessa nenhuma necessidade alheia; uma vida de avareza, ou uma vida de gozo".

Desse modo, compreende-se em que consiste essa "determinação geral" (allgemeine Bestimmung) da vontade expressa na terceira definição. Sem alcançar esta precisa generalidade, a máxima considerada revela-se, na verdade, uma regra específica ou propósito. Que a máxima não possa ser apenas uma regra específica também está indicado na terceira definição, posto que Kant afirma que a máxima pode subsumir “simples regras práticas”. Uma regra particular não pode conter sob si outras regras particulares. 
Disso brota uma consequência importante. Os conhecidos casos de falso-positivos e falso-negativos do teste fazem passar por máximas o que, na verdade, são apenas regras e propósitos. Jogar tênis aos domingos de manhã ou comprar trenzinhos de brinquedo na intenção de jamais vender algum ${ }^{12}$ indicam apenas regras particulares de comportamento, às quais não se aplica o teste de universalizabilidade. Qualquer regra específica pode gerar problemas ao teste, justamente pelo grau de especificidade que possui. Ocorre, porém, que o teste não convém a elas. Ele é um teste para avaliar a permissibilidade da máxima e, neste quesito, funciona corretamente.

Também não é necessário entrar no mérito da polêmica em torno dos exemplos que o próprio Kant apresentou na Segunda Seção da Fundamentação. Deixando de lado a intrincada questão do uso kantiano de premissas de caráter teleológico e finalista em seus diversos argumentos, que foge ao escopo deste artigo, é possível perceber que o teste da universalizabilidade pode ser corretamente aplicado aos exemplos oferecidos pelo filósofo, sem lançar mão daquelas premissas. $\mathrm{O}$ uso de tais premissas, todavia, não deixa de indicar que o teste não é tão simples quanto o filósofo o celebrara no final da Primeira Seção (cf. GMS 4: 403). É preciso discernir bem se o motivo em questão é, com efeito, uma máxima ou apenas uma regra de vida.

\section{REFERÊNCIAS}

ALLISON, Henry E. Kant's Groundwork for the Metaphysics of Morals: a commentary. Oxford: Oxford University Press, 2011.

AUNE, Bruce. Kant's Theory of Morals. Princeton: Princeton University Press, 1979.

BITTNER, Rüdiger. Máximas. Studia Kantiana, n. 5, p. 7-26, nov. 2003.

HEGEL, George Wilhelm Friedrich. Fenomenologia do espírito. Petrópolis: Vozes; Bragança Paulista: Editora Universitária São Francisco, 2011.

HERMAN, Barbara. The practice of moral judgement. Cambridge: Harvard University Press, 1993.

KANT, Immanuel. Fundamentação da metafísica dos costumes. Trad. Paulo Quintela. Lisboa: Edições 70, 2011.

\footnotetext{
12 Bruce Aune (1979, p. 122) também já indicava que o referido exemplo, pela sua extrema especificidade, não poderia ser considerado como uma máxima.
} 
KANT, Immanuel. Grundlegung zur Metaphysik der Sitten. Herausgegeben von Wilhelm Weischedel. Frankfurt: Suhrkamp Verlag, 2012.

KANT, Immanuel. Kritik der praktischen Vernunft. Herausgegeben von Wilhelm Weischedel. Frankfurt: Suhrkamp Verlag, 2012.

KANT, Immanuel. Kritik der reinen Vernunft. Hambur: Verlag von Felix Meiner, 1956.

MILL, John Stuart. Utilitarianism. In: ROBSON, J. M. (Ed.). Essays on ethics, religion and society. Toronto: University of Toronto Press, 1969, p. 203-260.

ROSS, David. Kant's ethical theory: a commentary on the Groundwork of the metaphysics of morals. Oxford: Clarendon Press, 1954.

SCHOPENHAUER, Arthur. The world as will and representation. Trad. E. F. J. Payne. New York: Dover Publications Inc., 1969. v. 1.

WOOD, Allen W. Kant's ethical thought. Cambridge: Cambridge University Press, 1999. 